\section{BOOK REVIEW}

The ECG in practice. John $\mathbf{R}$ Hampton. (Pp 332; £8.95). Edinburgh: Churchill Livingstone, 1992. ISBN 0-443-04506-2.

In many ways this book achieves the author's intention of providing a concise and practical guide to clinical interpretation of the electrocardiogram. The book is compact, and small enough to fit into a white coat, it has excellent indexing, including an index of all diagrams, and good quality ECG examples are featured throughout. Professor Hampton spends an appropriate amount of detail on the interpretation of the normal or slightly abnormal ECG and has dedicated a section to the effects of noncardiac disease on the electrocardiogram. In most chapters the clinical approach of the book shows clear advantages over the "textbook style" seen in specialist texts; the advantages and disadvantages of the ECG in relation to the clinical situation are shown and much lateral thinking is employed. The subjects of chest pain and breathlessness associated with ECG abnormalities are discussed in separate sections with a good range of electrocardiographic examples seen in pulmonary and cardiac diseases.

Professor Hampton has chosen to extend the principles of his previous book The ECG Made Easy by presenting electrocardiographic patterns associated with clinical sit- uations without reference to underlying physiology. The physiological principles of the electrocardiogram are either omitted (for example, Einthoven's triangle, Q waves) or presented as an optional chapter at the end of the book. This unconventional approach certainly gives brevity to subjects such as myocardial infarction, but does so at the expense of a full understanding of the normal and the abnormal electrocardiogram: the ECG configuration in both have to be memorised-yet this would not be necessary if a little theory was known. For example a simple reference to a diagram of electric axis would clarify why a predominantly upright QRS complex in limb lead aVL is a common pattern seen in the normal individual.

Atrial arrhythmia and atrioventricular tachycardia pose one of the greatest challenges to medical undergraduates and junior doctors. An understanding of the normal pattern of cardiac conduction is helpful before the electrocardiographic features of re-entrant tachycardia, accessory pathways, aberrant AV conduction, and heart block become clear, yet the subject is discussed only briefly in the final chapter ("The physiological basis of the ECG"). AV nodal blockade by a bolus of intravenous adenosine is not discussed as a diagnostic tool. Its use may be essential in distinguishing ventricular tachycardia from supraventricular tachycardia at the bedside and its role in the diagnosis of AV re-entrant tachycardia is well established, yet adenosine is not mentioned in the diagnostic section on palpitation and syncope. Later on in this same chapter the author gives guidance on the drug treatment of arrhythmias Intravenous flecainide is recommended as third line treatment for ventricular tachycardia and intravenous atenolol as second line therapy for both ventricular tachycardia and atrial fibrillation. The use of such drugs in these situations is controversial and leaves the reader with the impression that drug therapy of arrhythmia is beyond the scope of this book.

In summary this pocket sized volume complements The ECG Made Easy and will be best employed in the hands of those who have had useful experience of the companion book. A good collection of ECG examples is included, with excellent crossreferencing. Any reader expecting to see basic physiological principles applied to bedside electrocardiography will be disappointed, but may still find this book a useful supplement to other, less clinically based textbooks.

E LEATHAM

If you wish to order or require further information regarding the titles reviewed here, please write to or telephone the BMF Bookshop, $P O$ Box 295, London WC1H 97R. Tel: 071-383 6244. Fax 071-383 6662. Books are supplied post free in the UK and for BFPO addresses. Overseas customers should add $15 \%$ for postage and packing. Payment can be made by cheque in sterling drawn on a UK bank or by credit card (MasterCard, VISA or American Express) stating card number, expiry.date and your full name. (The price and availability are occasionally subject to revision by the Publishers).

\title{
BRITISH CARDIAC SOCIETY NEWSLETTER
}

\section{Changes to the Newsletter}

The Newsletter appears to be fulfilling its self-appointed task of keeping the members of the British Cardiac Society informed on matters of moment. As part of this process, the chairmen of Society committees, and our Affiliated Groups, have been asked to report briefly on the work of the committees/groups on a regular basis, as follows:

\section{Committee \\ Joint Audit}

Data Management

Epidemiology \& Prevention

Medical Practice

Programme

Technicians

Training \& Manpower

Publications

Ethical \& Legal

Postgraduate Adviser

Read Codes

\section{Affiliated Groups}

British Cardiovascular Intervention Society

British Pacing \& Electrophysiology Group

British Society of Echocardiography

British Nuclear Cardiology Group

British Paediatric Cardiac Association

Most of the committees have already accepted this proposal (none has declined), and so it is hoped to keep members regularly up to date on these activities. The dates have been selected, where applicable, to link with significant dates in the calendar of each activity, taking account of the fact that copy is required $\mathbf{2}$ months in advance of publication.

This schedule does not preclude, of course, our receiving news from any source at any time.

$\begin{array}{ll}\begin{array}{l}\text { Chairman } \\ \text { Prof D de Bono }\end{array} & \text { BHJ issue } \\ \text { June \& December } \\ \text { Prof D W Wood } & \text { July \& January } \\ \text { Dr Kim Fox } & \text { August \& February } \\ \text { Prof A Henderson } & \text { September \& March } \\ \text { Dr D Dymond } & \text { April } \\ \text { Dr M Webb-Peploe } & \text { Junember \& May } \\ \text { Dr D Dymond } & \text { January } \\ \text { Prof Keith Fox } & \text { February } \\ \text { Dr H Swanton } & \text { October } \\ \text { Dr M Towers } & \text { October \& April }\end{array}$

Dr M Rothman

Dr A Nathan

Dr M Monaghan

Dr $S$ Walton

Dr S Quresh

August \& February September \& March October \& April

November \& May

December \& June
Report from the Joint Audit Committee The confidential inquiry into complications from cardiac catheterisation (CECC) is now well established with a large number of participating centres. The project entails establishment of the mechanism for the collection and verification of data on the types of procedure and complications. The committee is of the view that eventually all catheterisation laboratories should be encouraged to participate, and that the approach to monitoring complications should be part of the Specialist Advisory Committee assessment for senior registrar posts. Feedback from several units has indicated that the monthly order is easy to maintain and has greatly increased awareness of complications, minor and major, leading to a general tightening of procedures. If your centre is not enrolled and you would like it to be please contact David de Bono at Glenfield General Hospital, Groby Road, Leicester, LE3 9QP.

Thirty one cardiac care units are collectThat for John Birkhead's study on time to thrombolysis. As with the CECC, the routine collection of these data has led to a marked improvement in the performance of many units. It is worth mentioning that many purchasers are now requiring a target time to thrombolysis as one aspect of the specified level of care for patients with acute myocardial infarction.

After a successful series of workshops on guidelines for the management of angina (shortly to be published) which was sponsored jointly by the Royal College of Physicians Research Unit and the British Cardiac Society, the Joint Audit Committee 